\title{
Relationship between changes in intraluminal pressure and transmural potential difference in the human and canine jejunum in vivo
}

\author{
N. W. READ, R. H. SMALLWOOD, R. J. LEVIN ${ }^{1}$, C. D. HOLDSWORTH, AND \\ B. H. BROWN
}

From the Departments of Medicine, Medical Physics, and Physiology, University of Sheffield, Sheffield

SUMMARY Recordings of transmural potential difference (PD) across the jejunum of conscious man in situ are characterised by spontaneous fluctuations of up to $10 \mathrm{mV}$. In 25 of 31 subjects (comprising seven normal controls and 24 patients under investigation for malabsorption, six of whom had coeliac disease) we observed a clear association between these fluctuations and changes in intraluminal pressure recorded at the same site. The most frequent PD changes were associated with type III pressure waves. These consisted predominantly of large waves $(3 \cdot 1 \pm 0 \cdot 1 \mathrm{mV}$; mean \pm SEM, $n=317)$ which reached maximal amplitude approximately 45 seconds after the pressure peak and had a duration of $120 \pm 3 \mathrm{~s}$, but also included less frequent spikes $(0.5 \pm 0 \cdot 1 \mathrm{mV}$; $\mathrm{n}=110$ ) concurrent with the pressure wave with a duration of $5 \pm 1 \mathrm{~s}$. Although by recording at two sites in the jejunum $10 \mathrm{~cm}$ apart we were able to demonstrate that the type III pressure waves appeared to be propagated aborally at a median rate of $60 \mathrm{~cm}$ per minute, the apparent rates of propagation of the corresponding PD waves were much more variable. The largest PD changes $(7.8 \pm 0.4 \mathrm{mV} ; \mathrm{n}=19)$, lasting several minutes, were found in association with runs of type I waves (basic rhythm) superimposed on a type III wave. Both pressure and PD activities were suppressed by intramuscular propantheline bromide. Intraluminal pilocarpine caused a transient rise in PD not always accompanied by a change in pressure. Distension of the jejunum by rapid injection of a bolus of isotonic sodium chloride produced a delayed rise in the PD which could be prevented by prior administration of propantheline bromide. Experiments using ThiryVella loops of proximal jejunum in conscious dogs confirmed the effect of jejunal distension on the PD and also demonstrated that spontaneous retching is preceded by an increase in the PD.

Consideration of these results in conjunction with data from other workers suggests the hypothesis that the larger spontaneous fluctuations in transmural PD in the jejunum of conscious man are caused by changes in electrogenic secretion associated with intestinal motility and mediated by cholinergic mechanisms. The possible association of increased secretory activity with motility may have functions of lubrication as well as diluting and mixing the chyme for easier digestion and absorption.

Several studies have noted that recordings of transmural PD in the human jejunum in situ are unstable (Fordtran et al., 1968; Wingate et al., 1973; Read et al., 1974), being characterised by irregular fluctuations which can last for several minutes and attain amplitudes of $10 \mathrm{mV}$. These apparently spontaneous

\footnotetext{
'Address for reprint requests: Dr R. J. Levin, Department of Physiology, University of Sheffield, Sheffield S10 2TN.
}

Received for publication 10 September 1976 changes have been a major obstacle to the investigation of enterocyte transfer processes by electrical methods. Our observation that propantheline bromide (Pro-Banthine) inhibits these fluctuations (Read et al., 1974; 1976) indicated that they may be related to intestinal motility, which is also inhibited by this drug. We have investigated this possibility by recording the transmural $P D$ and intraluminal pressure at the same site in both the proximal jejunum in conscious humans and jejunal loops of 
conscious dogs. A preliminary account of part of this work has been published (Brown et al., 1976).

\section{Methods}

MEASUREMENTS IN HUMAN SUBJECTS

Recordings were carried out on seven healthy volunteers and 24 patients under investigation for malabsorption, six of whom had coeliac disease.

After an overnight fast, each subject swallowed the intestinal tube illustrated in Fig. 1. The end of the tube was positioned approximately $5 \mathrm{~cm}$ beyond the duodenojejunal flexure with the aid of image intensification and television screening. When the tube was in situ a solution of $154 \mathrm{mM}$ sodium chloride was infused at $0.2 \mathrm{ml}$ per minute by means of a constant infusion syringe pump (Sage Instruments model 355). The luminal fluid was allowed to siphon freely into a plastic bucket at ground level. In order to avoid short circuits, the end of the siphonage tube was kept free of the fluid in the bucket, which stood on a dry rubber surface. Intraluminal pressure was measured using a strain gauge transducer (Bell \& Howell type 4-422-0001) connected via a side arm to the saline infusion column. For measurements of transmural PD the same infusion column acted as a flowing intraluminal electrode. The reference electrode consisted of a Medicut (Sherwood Medical Industries, Ltd) plastic cannula filled with $154 \mathrm{mM}$ sodium chloride and inserted under the skin of the forearm. Both electrodes were connected via agarsalt bridges (3M $\mathrm{KCl}$ in $3 \%$ agar) through paired calomel half-cells arranged back-to-back across the input terminals of a battery powered electrometer (Keithley model 602). The measurement of pressure and PD through the same infusion column ensured that both were recorded from the same site in the jejunum.

The outputs from the electrometer and the transducer were filtered using low pass electronic filters ( $6 \mathrm{~dB} /$ octave) with time constants of five seconds to reduce 50 Hertz AC mains interference, respiration, ECG, and intestinal myoelectrical activity. After suitable amplification the signals were displayed on a four channel chart recorder (Watanabe multicorder type MC 641-4L) to yield a permanent record, and stored on magnetic tape (Racal store 4 recorder) for further analysis by computer.

The tests were carried out in a quiet room with a low level of extraneous electrical interference. Any gross movements of the subject or manipulations by the operator were noted on the chart record and the tape.

The length of recording in each subject varied from 45 to 150 minutes and included a period towards the end of each experiment when the effects of an intra-

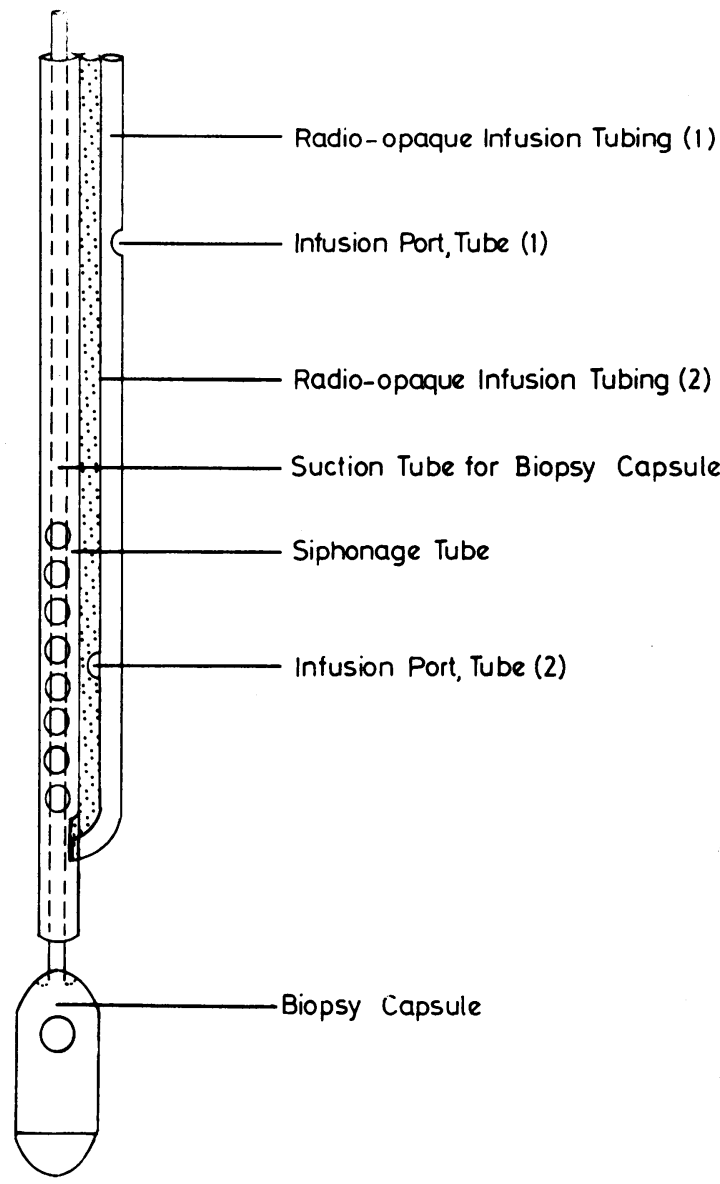

Fig. 1 The distal end of the intestinal tube. This consists of a narrow radio-opaque infusion tube (2) cemented to a wider and stiffer siphonage tube (Anlar type 20) perforated for $2 \mathrm{~cm}$ on either side of the infusion port. In six subjects the attachment of another radio-opaque tube (1) with an outlet $10 \mathrm{~cm}$ above the first infusion port allowed us to record from two sites in the jejunum simultaneously. The incorporation of a biopsy capsule (Crosby and Kugler, 1957) with its suction tubing (dotted lines) threaded through the siphonage tube enabled a specimen of jejunal mucosa to be obtained from the patients immediately after the period of recording and also acted as a weight to facilitate passage of the tube into the jejunum.

muscular injection of $30 \mathrm{mg}$ propantheline bromide were studied.

In a few subjects we investigated the changes in the PD and pressure produced by: (1) luminal administration of $5 \mathrm{mg}$ pilocarpine in $5 \mathrm{ml} 0.9 \% \mathrm{NaCl}$; (2) distension of the jejunum by rapid injection of 50 $\mathrm{ml}$ isotonic sodium chloride (prewarmed to $37^{\circ} \mathrm{C}$ ) via the infusion tube; and (3) reversal of the luminal 
polarity by infusion of an isosmotic solution containing $100 \mathrm{mM}$ mannitol in $104 \mathrm{mM}$ sodium chloride.

Each record was analysed by hand in terms of the amplitudes of the different types of PD fluctuations and for the time relationships between the pressure and PD changes. In addition, off-line cross-correlation and frequency analysis were carried out by computer on 13 tape recordings. For the crosscorrelation, a Biomac 1010 digital analyser with a 504A correlator unit was employed. The signals were filtered (high pass $0.016 \mathrm{~Hz}, 6 \mathrm{~dB} /$ octave, low pass $1 \mathrm{~Hz}, 24 \mathrm{~dB} /$ octave) and suitably amplified before correlating. Successive 10 minutes stretches of record were cross-correlated with a maximum delay of 122 seconds and an integration time of 500 seconds. Frequency analysis was carried out by performing fast Fourier transforms on 10 minute stretches of data using a Data General Nova minicomputer. The signals were filtered (high pass 0.0016 $\mathrm{Hz}, 6 \mathrm{~dB} /$ octave; low pass $0.21 \mathrm{~Hz}, 24 \mathrm{~dB} /$ octave) and suitably amplified before digitising to 8 bits accuracy at a sampling rate of $2 \cdot 34 \mathrm{~s} /$ point. Fast Fourier transforms were calculated giving a frequency spectrum from $0.1 \mathrm{cycles} / \mathrm{min}$ to 12.8 cycles/ $\min$ in $0 \cdot 1$ cycles/min increments.

\section{MEASUREMENTS IN DOG}

Recordings of intraluminal pressure and transmural PD were also carried out using $30 \mathrm{~cm}$ Thiry-Vella loops of the proximal jejunum in two healthy conscious dogs. The animals were trained to lie on their sides without any restraint for the duration of the experiment. Urinary catheters (Foley type size 14) were inserted into both ends of the loop and the distal balloons of each catheter were inflated with 5 $\mathrm{ml}$ of air. When gentle traction was applied to each balloon this volume was sufficient to prevent leakage from the loop without causing obvious discomfort to the animal. A solution of $154 \mathrm{mM}$ sodium chloride was then infused by gravity feed at a constant rate of $1 \mathrm{ml} / \mathrm{min}$ through the proximal catheter and allowed to drain freely from the loop via the distal catheter. Recordings of intraluminal pressure were carried out by means of a strain gauge transducer (Bell \& Howell type 4-422-0001) situated on a side arm of the infusion column. This was connected via an amplifier to a two channel recorder (Telsec Model $700 \mathrm{~T}$ ). For measurements of transmural PD the infusion column acted as a flowing intraluminal electrode, while the reference electrode was an intravenous cannula inserted in the cephalic vein and infused with $154 \mathrm{mM} \mathrm{NaCl}$ at $0.5 \mathrm{ml}$ per minute. These electrodes were connected via agar-salt bridges to a battery-powered electrometer (Keithley Model 602), the output of which was connected to the recorder. Considerable problems were encountered in obtaining stable records in the dog. These were partially solved by: (1) placing the animal in a Faraday cage; (2) connecting the dog to earth by means of a flat metal plate moistened with electrode jelly and attached to the shaved skin of one hind leg; and (3) avoiding stimuli that caused the dog to wag its tail!

The effect of distension of the loop on pressure and $P D$ recordings was investigated by occluding the outflow catheter by means of a gate clip.

\section{EXPERIMENTS in vitro}

Experiments were undertaken to assess whether increases in pressure could cause changes in PD by affecting the agar-salt bridge in the flowing electrode. No significant effects of increases of pressure up to $100 \mathrm{~cm}$ water were observed.

\section{Results}

IN MAN

In 25 out of 31 recordings $(81 \%)$ there was an apparent temporal relationship between spontaneous fluctuations in intraluminal pressure and changes in transmural PD (Fig. 2). Pressure changes produced by gross movements of the patient were never accompanied by large changes in PD. In the absence of pressure changes the PD records were stable.

The observed pressure waves together with the characteristics of their associated fluctuations in potential difference are listed in Table 1. Spontaneous PD fluctuations were for the most part associated with discrete multiphasic pressure complexes or type III waves (Foulk et al., 1954). These changes in PD were of two types: (1) small spikes $(0.5 \pm 0 \cdot 1$ $\mathrm{mV}$; mean \pm SEM) which occurred at the same time as the pressure wave, but were relatively uncommon; (2) larger, more frequent 'waves' $(3.1 \pm 0.1$ $\mathrm{mV}$ ) with a peak-to-peak delay of 45 seconds and mean duration of two minutes. Discrete, simple type I pressure waves (Foulk et al., 1954) were very rarely associated with changes in the transmural PD. However, the infrequent pattern consisting of runs of type I waves, superimposed on a type III wave (basic rhythm, Foulk et al., 1954) was always found in association with the largest changes in PD (Figs. 3, 5, and 6). These fluctuations could attain amplitudes of $14 \mathrm{mV}$, had an average duration of eight minutes, preceded the onset of the pressure change in most subjects, and were always followed by a considerable reduction in pressure and PD activities compared with the earlier part of the trace (Figs. 3 and 5). In 12 out of 23 subjects they appeared after the administration of propantheline bromide (Fig. 5), but then the ensuing period of 


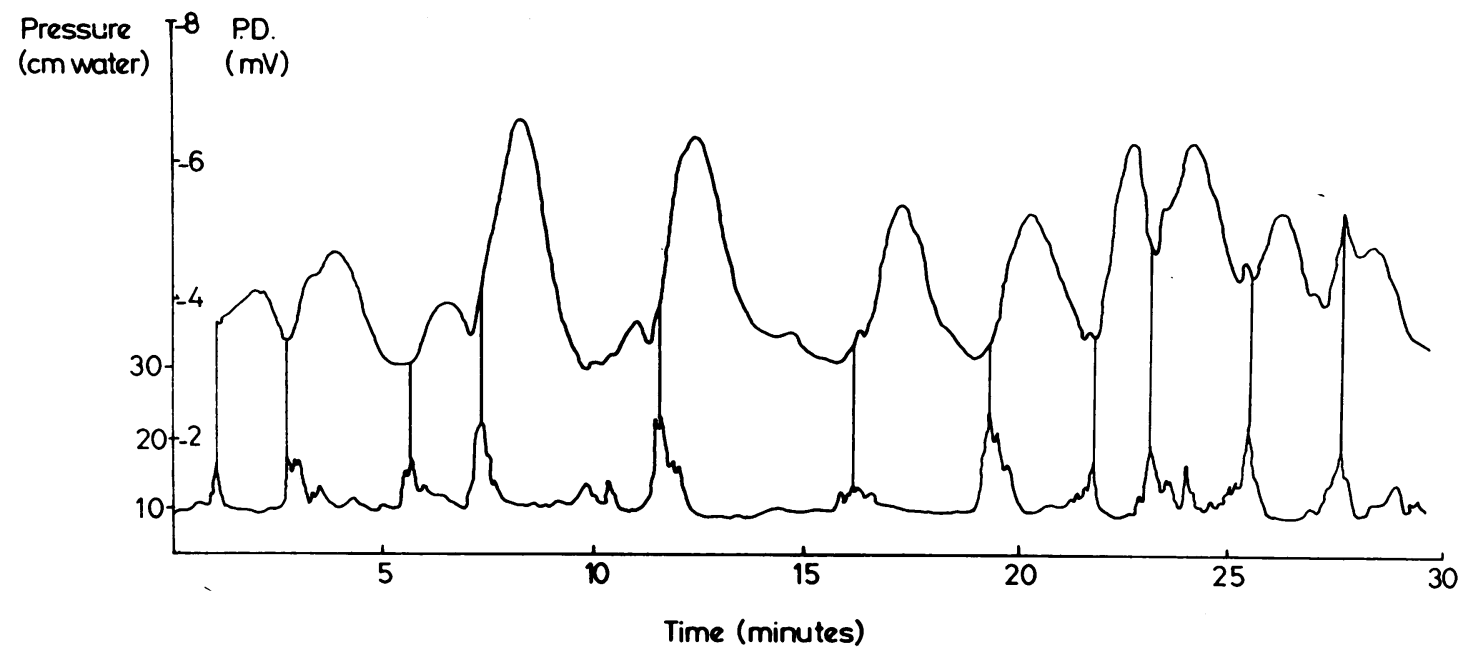

Fig. 2 Recordings of the intraluminal pressure (lower trace) and transmural PD (upper trace) from the jejunum of one patient with weight loss but no evidence of small bowel disease. Vertical lines have been drawn from the peaks of the pressure waves to emphasise the association of type III pressure complexes with large delayed PD waves and also with much smaller spikes.

Table 1 Pressure waves together with characteristics of associated fluctuations in potential difference observed in jejunum of conscious human subjects

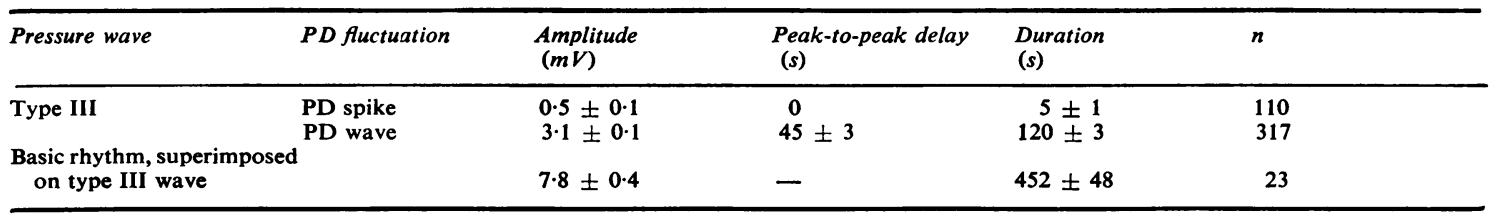

The results are expressed as the mean $\pm 1 \mathrm{SE}$ of the mean. $\mathrm{n}$ : number of waves analysed in each group
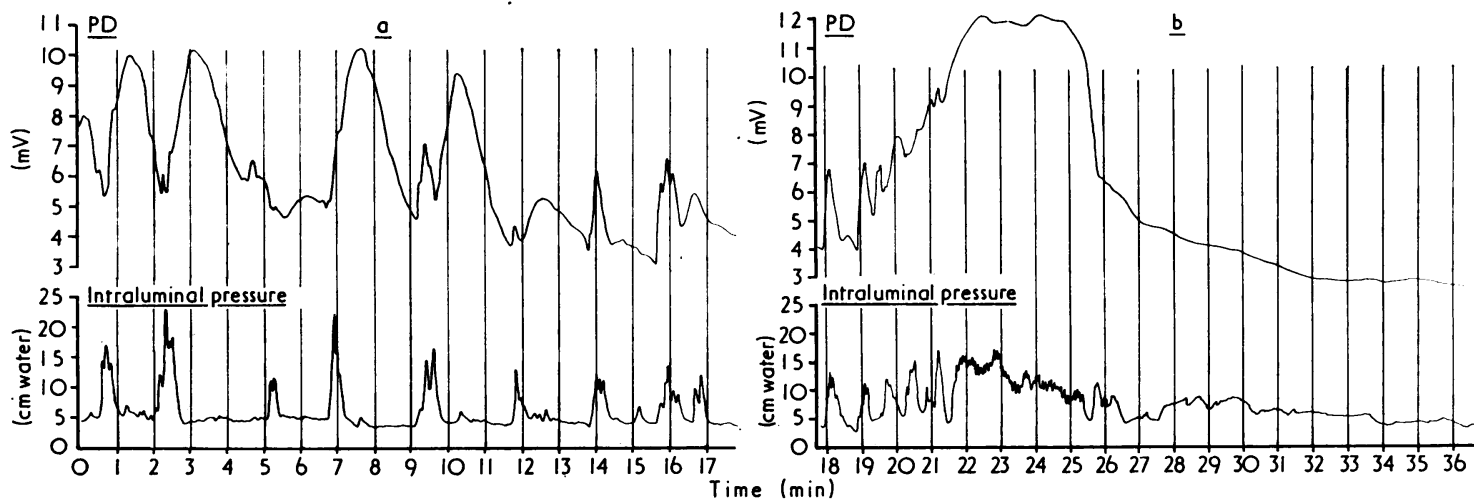

Fig. 3 Recordings of intraluminal pressure (lower trace) and transmural PD (upper trace) from the jejunum of one young man with aphthous ulceration of the mouth but no evidence of small intestinal disease. This record demonstrates four different types of pressure and PD activity. For the first 13 minutes the pressure trace consists of large discrete type III complexes separated by intervals of more than a minute and associated with large delayed $P D$ waves. Then as the frequency of the pressure complexes increases the PD record becomes increasingly dominated by spikes. After 19 minutes both pressure and PD baselines increase until in the 21st minute the pressure record takes the form of basic rhythm superimposed on a type III wave and there is a correspondingly large increase in the PD. Finally, at 26 minutes the pressure activity subsides and the PD falls to a steady baseline. Both records then remain quiescent for at east 15 minutes. 
quiescence exceeded 90 minutes compared with the much shorter periods (approximately 15 minutes) when this pattern occurred spontaneously (Figs. 3 and 6).

The preponderance of either PD spikes or PD waves in any record appeared to vary according to the pressure activity. In motility records characterised by discrete type III pressure waves separated by more than a minute, the electrical trace was composed largely of delayed PD waves with only insignificant PD spikes (Fig. 2). This type of activity was seen most clearly in patients with coeliac disease. Conversely, when the pressure record was particularly active, containing both type I and type III waves (Foulk et al., 1954) with few periods of quiescence, the electrical record exhibited larger and more frequent immediate PD spikes and less delayed PD waves. This type of record was observed most frequently in our normal subjects. In a few cases, both PD waves and spikes were seen in association with the same type III pressure wave. All of these features are seen in Fig. 3.

The relationship between type III pressure waves and the PD waves given in Table 1 was confirmed by computer cross-correlation, which gave a positive correlation with the pressure peak preceding the electrical peak by $41 \pm 3$ seconds. Frequency analysis of these fluctuations, however, did not show any evidence of periodicity.

Recording the PD and pressure at two sites separated by $10 \mathrm{~cm}$ (Fig. 4) in six subjects showed that the type III pressure waves appeared to be propagated at a median rate of $60 \mathrm{~cm}$ per minute, a rate very similar to that recorded by Friedman et al. (1965). Although the corresponding PD waves also showed evidence of propagation, the rates calculated from peak-to-peak delays showed considerable variation.

The intramuscular administration of propantheline bromide had two completely different effects on the pressure and PD records obtained from the human jejunum in situ. In all cases there was a prolonged ( $>90 \mathrm{~min}$ ) suppression of all pressure and PD fluctuations. This inhibition, however, was preceded in 16 out of 23 recordings ( $70 \%$ ) by an initial enhancement of both activities, which in 12 cases was associated with the pressure pattern of basic rhythm superimposed on a type III wave (Fig.

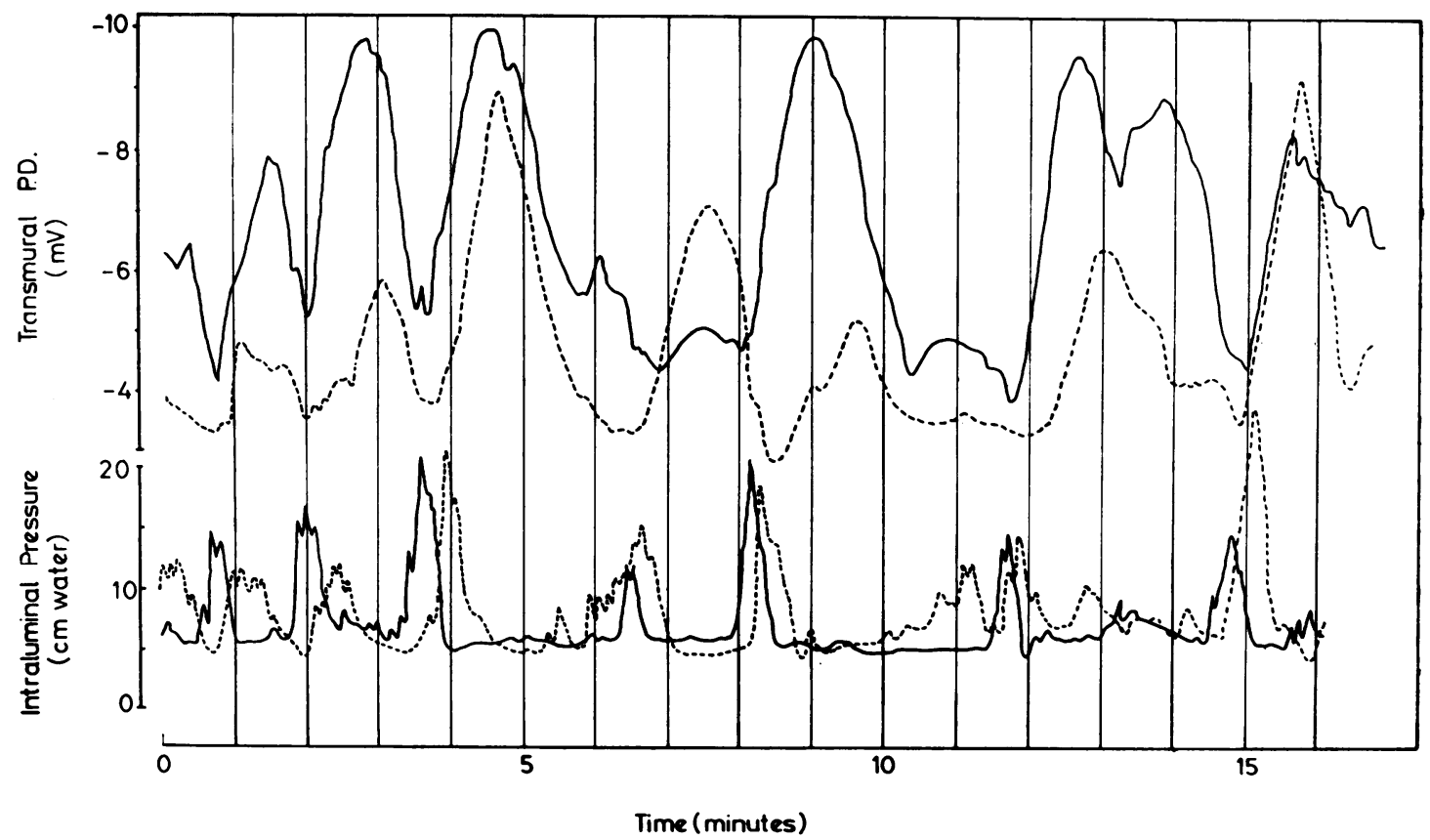

Fig. 4 Intraluminal pressures (lower traces) and transmural PDs (upper traces) recorded at the duodenojejunal flexure (-) and a point $10 \mathrm{~cm}$ distal (...) in a normal subject. The delay between pressure peaks at proximal and distal sites suggests propagation of these waves aborally at a median rate of $60 \mathrm{~cm}$ per minute. Although in most instances there is also a delay between proximal and distal PD peaks, the apparent rates of propagation are more variable. 


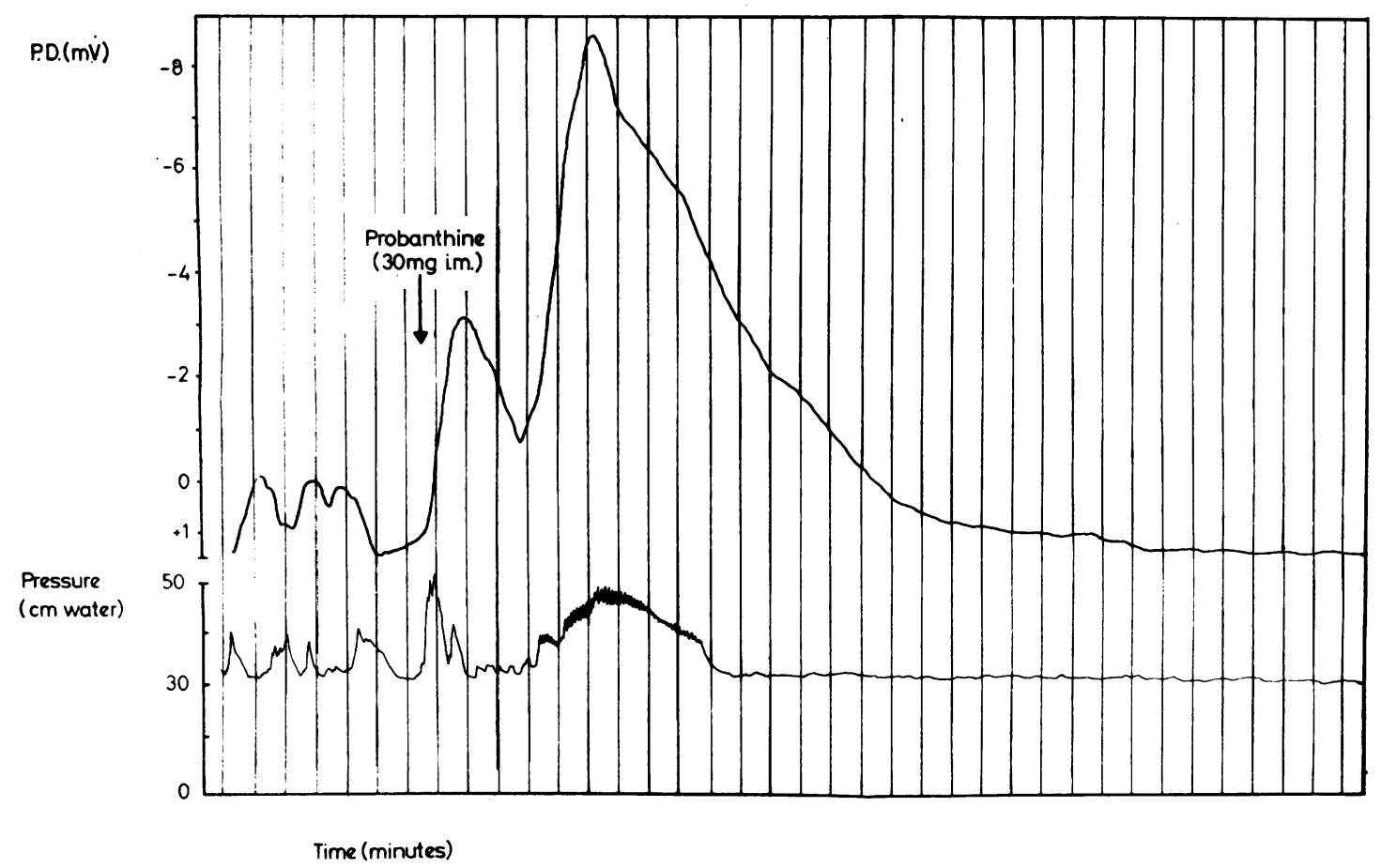

Fig. 5 The effect of an intramuscular injection of $30 \mathrm{mg}$ propantheline bromide (Probanthine) on transmural PD (upper trace) and intraluminal pressure (lower trace) from the jejunum of a normal subject. Approximately four minutes after the injection, the pressure increased and assumed the pattern of basic rhythm superimposed upon a type III wave. This was associated with a rise in PD, which reached a peak $8 \mathrm{mV}$ above the original level. After this initial enhancement the pressure fluctuations were suppressed and the PD slowly fell to reach a steady baseline. Both $P D$ and pressure then remained quiescent for approximately 90 minutes.

5). If we reduced the filter time constants from five seconds to 0.5 second during these changes, this revealed smaller regular fluctuations in PD occurring at the same frequency as the type I pressure waves (approximately 10 per minute) and actually superimposed on the large PD wave (Fig. 6). These were presumably caused by the myoelectrical slow wave and could be revealed in the same way, even when motility was completely suppressed by propantheline bromide (Fig. 7).

The intraluminal administration of pilocarpine in four subjects always produced a transient increase in the PD of approximately $4 \mathrm{mV}$ (Fig. 8). This was not usually associated with any change in pressure.

In four subjects, distension of the jejunum by rapid intraluminal injection of a saline bolus always produced a large PD wave (approximately $7 \mathrm{mV}$ ) the peak of which occurred some 60 seconds after the distension stimulus (Fig. 9). This PD wave was not seen if propantheline bromide was given before the jejunum was distended.
The preceding observations were made during infusion of the jejunal lumen with isotonic sodium chloride $(154 \mathrm{mM})$. Under these conditions the lumen was always a few millivolts negative to the subcutaneous reference site and fluctuations in PD always made the lumen more negative. When an isosmotic solution containing $104 \mathrm{mM}$ of sodium chloride and $100 \mathrm{mM}$ Mannitol was infused in two subjects to create a sodium diffusion gradient from blood to lumen, the polarity of the lumen reversed and became a few millivolts positive to the subcutaneous site. Despite this reversal of the luminal polarity, the orientation of the spontaneous PD fluctuations was unaltered.

Although in a preliminary study such as this it is not possible to establish clear distinctions between records from different clinical groups, two observations are noteworthy. Firstly, the association of discrete type III pressure waves and large delayed PD waves is most clearly observed in the coeliac group. In contrast, in normal subjects where the pres- 


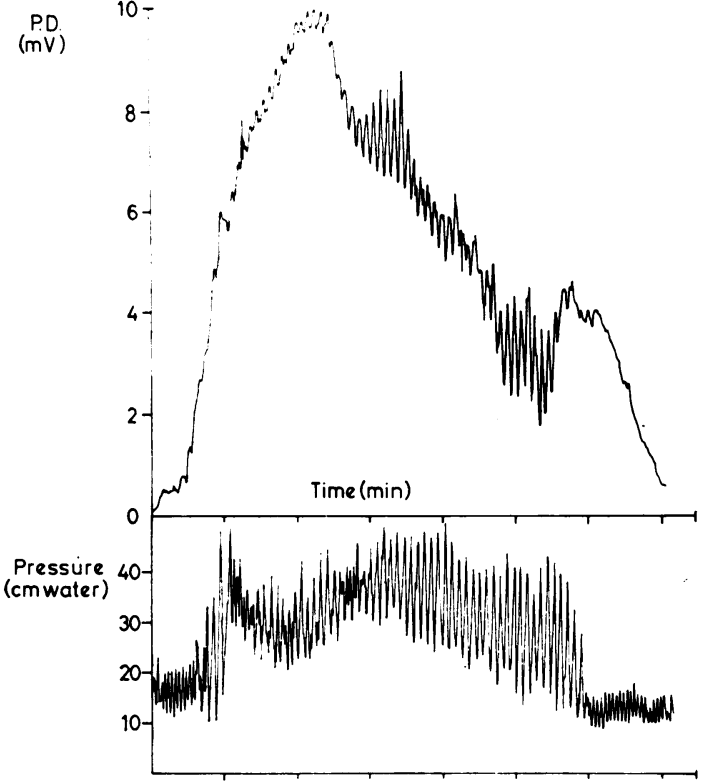

Fig. 6 Intraluminal pressure (lower trace) and transmural PD (upper trace) in one normal subject during a spontaneous period of basic rhythm superimposed on a type III wave. In this recording the time constant on the $P D$ filter was reduced from $5 s$ to $0.5 \mathrm{~s}$, revealing regular fluctuations in PD (approximately 10 per minute) which occurred at the same frequency as the pressure fluctuations and were actually superimposed on the large $P D$ wave. These fluctuations were not related to respiration, which occurred at a higher frequency (approximately 19 per minute) and can be seen on the pressure trace after the period of basic rhythm.

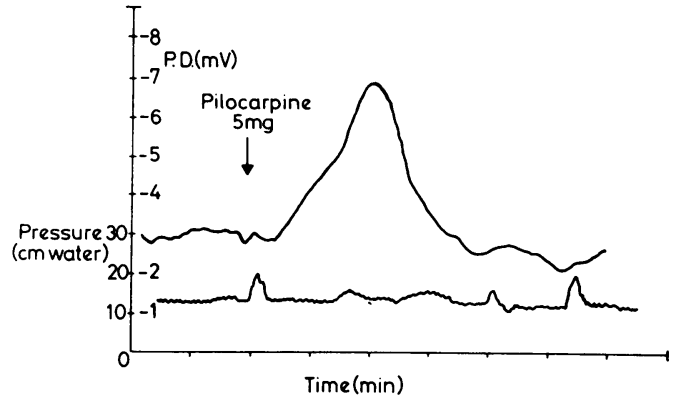

Fig. 8 The effect of an intraluminal injection of $5 \mathrm{mg}$ pilocarpine dissolved in $5 \mathrm{ml}$ normal saline (154 $\mathrm{mM}$ $\mathrm{NaCl}$ ) on the intraluminal pressure (lower trace) and transmural PD (upper trace) in a normal subject. Intraluminal administration of pilocarpine via the infusion tube resulted in an initial artefactual rise in pressure but no change in $P D$. This was followed by a transient rise in $P D$, but no change in pressure.

sure trace is more active, the PD record is more often a mixture of immediate spikes and delayed waves. Second, the PD waves are very significantly larger $(P<0.001)$ in patients with coeliac disease than in normal subjects or in all other patients studied (Table 2).

\section{IN DOG}

Although work on this preparation was originally carried out as a preliminary to studies in man, certain observations were made which have relevance to the interpretation of subsequent results from human studies. Firstly, distension of the loop

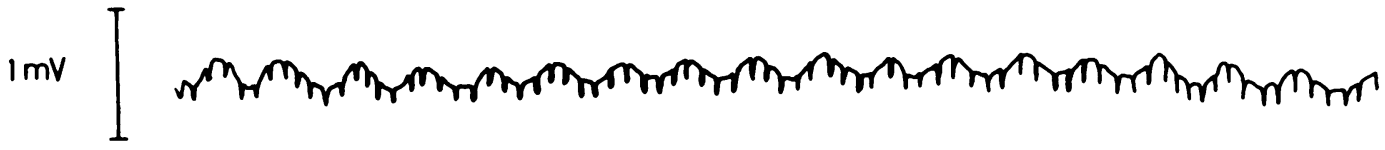

$10 \mathrm{~cm}$
Water

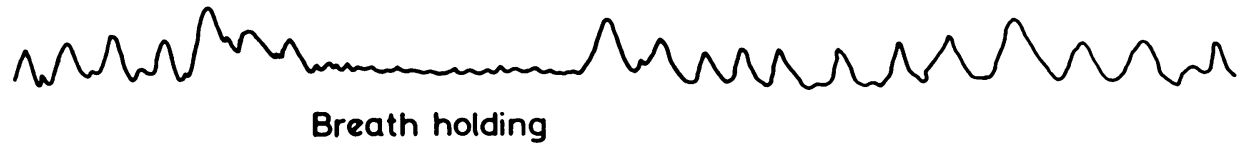

Fig. 7 Unfiltered recordings of intraluminal pressure (lower trace) and transmural PD (upper trace) from the jejunum of a patient with diabetes mellitus, who had previously received an intramuscular injection of propantheline bromide. The pressure trace demonstrates fluctuations at approximately 14 per minute related to respiration. The electrical record, however, demonstrates regular fuctuations at approximately 11 per minute, which are clearly not related to respiration and are presumably caused by the myoelectrical slow wave. The ECG can be seen superimposed on the electrical fluctuations. Both pressure and PD fluctuations would normally be suppressed by the electronic filters. (Time constant five seconds). 


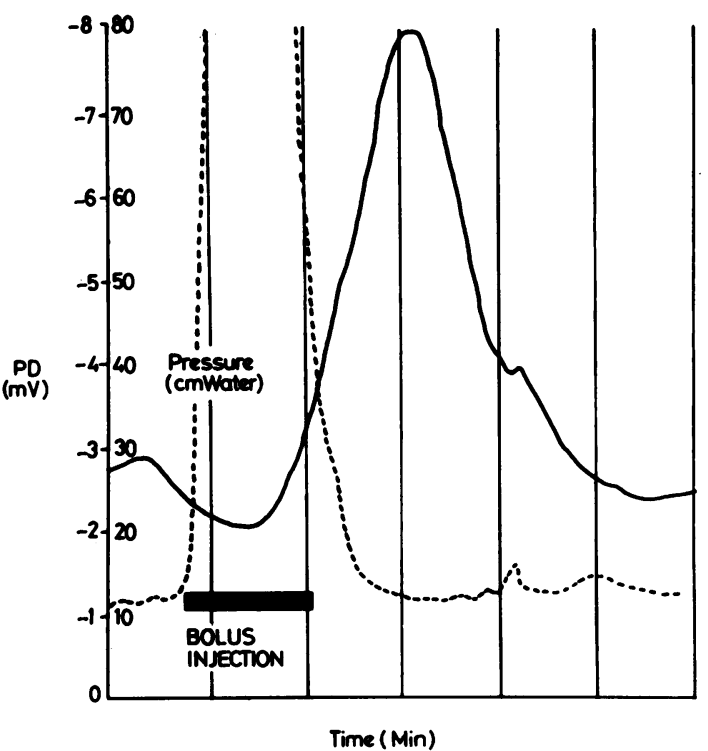

Fig. 9 The effect of distension of the jejunum of a normal subject by bolus injection of $50 \mathrm{ml}$ of an isotonic solution of sodium chloride via the infusion tube. The injection makes the intraluminal pressure (....) artefactually high, but the time course of the distension can be clearly observed. The PD peak did not occur until approximately 60 seconds after the distension stimulus.

Table 2 Amplitude of PD waves related to type III pressure waves in seven normal subjects, six patients with coeliac disease, and 18 other patients under investigation for malabsorption, who had normal jejunal biopsy

\begin{tabular}{|c|c|c|c|}
\hline \multirow[t]{2}{*}{ Group } & \multicolumn{3}{|c|}{$P D$ wave amplitude } \\
\hline & $M e a n \pm S E M$ & $n$ & \\
\hline $\begin{array}{l}\text { Normal (7) } \\
\text { Coeliac (6) } \\
\text { Other patients (18) }\end{array}$ & $\begin{array}{l}2.3 \pm 0.2 \\
5 \cdot 1 \pm 0.3 \\
2 \cdot 8 \pm 0.1\end{array}$ & $\left.\begin{array}{r}80 \\
77 \\
160\end{array}\right\}$ & $\begin{array}{l}P<0.001 \\
P<0.001\end{array}$ \\
\hline
\end{tabular}

$\mathrm{n}$ refers to the number of waves analysed in each group. The degree of significance was calculated using Student's $t$ test for unpaired data

produced by occluding the distal catheter resulted in an increase in intraluminal pressure accompanied by a rise in PD of several millivolts, which followed the pressure peak by approximately 60 seconds (Fig. 10). Second, the infrequent occurrence of spontaneous retching was always preceded for more than a minute by an increase in PD (Fig. 11).

\section{Discussion}

In this study we have clearly demonstrated a temporal relationship between fluctuations in transmural PD

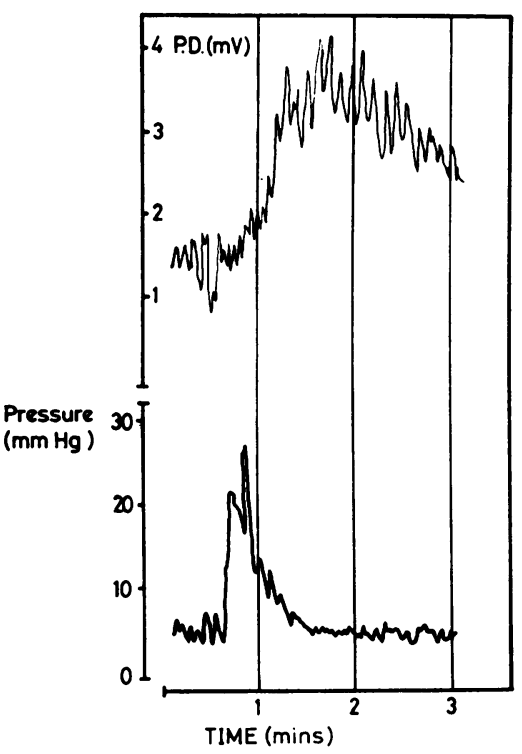

Fig. 10 The effect of transient distension of the jejunal loop of the conscious dog, produced by occluding the outflow catheter. This caused an increase in pressure (lower trace) of approximately one minute after the pressure peak. The relatively high frequency fluctuations (approximately 10 per minute) in these unfiltered records are related to respiration.

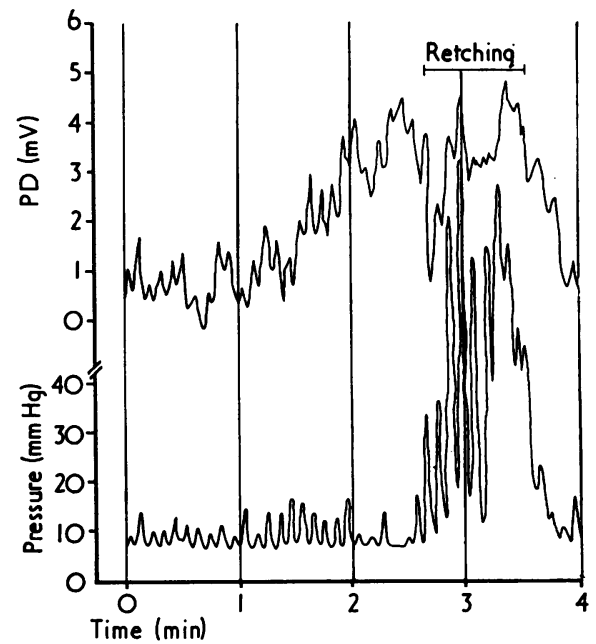

Fig. 11 The effect of nausea and retching on the intraluminal pressure (lower trace) and transmural PD (upper trace) recorded from the canine jejunum in vivo. Retching was indicated by the large amplitude fluctuations in pressure caused by abdominal contractions and this was preceded for about a minute a gradual rise in PD to a level 2-3 $\mathrm{mV}$ above the baseline. 
and changes in intraluminal pressure recorded in the human jejunum in situ. A similar relationship has recently been observed in the rat colon in vivo (Gerard et al., 1975). Wingate and his colleagues (1974) have investigated the nature of the spontaneous PD changes in the duodenum using an isolated, perfused preparation of canine stomach and duodenum. Although they demonstrated an association between fluctuations of intestinal transmural PD and pressure in this preparation, their PD changes were regular ( 20 per minute), of relatively low amplitude $( \pm 1 \mathrm{mV})$ and were apparently caused by the myoelectrical slow wave. Thus it is clear that the PD changes recorded in their preparation are totally unlike the large irregular fluctuations of several minutes duration which we have recorded in the human jejunum in situ. By reducing the filter time constant we have in fact demonstrated small regular fluctuations occurring at the same frequency as the jejunal myoelectrical slow wave (10 per minute) actually superimposed on the large PD fluctuations (Fig. 6). Further evidence that these two types of PD fluctuation are completely separate phenomena is that the administration of the cholinergic inhibitor, propantheline bromide, had no effect on the small regular fluctuations related to the myoelectrical slow wave (Fig. 7), even though it completely suppressed the large PD fluctuations and also intestinal motility (Fig. 5).

What then is the mechanism underlying the spontaneous changes in transmural PD recorded in the human jejunum? Consideration of the mechanical events during a peristaltic contraction suggests several mechanisms which could result in changes in transmural PD. These include: (1) alterations in the mucosal electrical resistance; (2) changes in the spatial relationship between electrode and mucosa; and (3) a direct effect of increases in pressure on the electrode. Such mechanisms would create simultaneous changes in pressure and PD and thus should be responsible only for the PD spikes in our records (Table 1). Our observation that changing the luminal polarity did not alter the orientation of the PD waves is further evidence against their mediation by changes in mucosal electrical resistance. Regarding alterations in the spatial relationship between electrode and mucosa, we found that slow withdrawal of the tube from the jejunum in 20 subjects had little effect on the magnitude of the PD until the electrode reached the descending duodenum. Finally, increases in pressure on the 'luminal electrode' in vitro many times higher than those recorded in vivo had absolutely no effect on the PD. Thus, the relationship between pressure and PD is unlikely to be a direct mechanical one, but is perhaps mediated by the release of some chemical transmitter, possibly acetylcholine, influencing electrogenic transport.

Support for this hypothesis comes from several sources. Hardcastle and Eggenton (1973) found that acetylcholine produced an increase in the rat transjejunal PD, which could be blocked by atropine. We have observed a similar response in man with luminal infusion of another cholinergic agent, pilocarpine (Fig. 8). Acetylcholine is released by distension of the guinea-pig ileum in vitro (Kazic and Varagic, 1968), suggesting that distension of the intestine should also increase the transmural PD. We have shown that this occurs in the jejunum of both conscious man and dog, while Hardcastle and Hardcastle (personal communication) have observed a similar effect in vivo in the anaesthetised rat. In man and rat, the increase in PD by distension can be blocked by prior administration of cholinergic inhibitors, but in the rat the ganglion blocker pentolinium had no effect (Hardcastle and Hardcastle, 1976). Therefore the data suggest that increased tension in the intestinal wall stimulates the release of acetylcholine which then alters the PD.

How does the acetylcholine alter the PD? If the intestinal mucosa acts as an ohmic resistor, variations in the transmural PD can occur as a result of either changes in the electrical resistance of the mucosa or alterations in ion transfer mechanisms producing a change in current or both. As there is no evidence for acetylcholine changing intestinal electrical resistance, it presumably alters ion transfer mechanisms. Because the induced PD change is always in the direction of enhancing the negativity of the lumen, it must occur as a result of either enhanced anion secretion or cation absorption, or both. There is much evidence to show that increases in intestinal motility (Gregory, 1962; Cooke, 1967; Matuchansky et al., 1972), distension of the lumen (Herrin and Meek, 1933), administration of cholinergic agents (Florey et al., 1941), induction of nausea (Gregory, 1947), and stimulation of the vagus (Savitch and Sochestvensky, 1917; Wright et al., 1940) are all associated with increases in intestinal secretion. All these, except the latter, have been shown to increase the transjejunal PD. The studies of Tidball (1961) using canine jejunum in vivo clearly demonstrated that cholinergically induced secretion could be electrogenic. These observations have been confirmed by Hubel (1973) in the jejunum of the anaesthetised rat and also by Turnberg and his colleagues (1976) using the human jejunum and ileum in vitro.

To summarise, there is ample experimental data to support the hypothesis that large spontaneous fluctuations in transmural PD in the human jejunum are caused by changes in electrogenic secretion associated with intestinal motility and mediated by 
cholinergic mechanisms (local or vagal or both). In this respect, the finding of larger PD waves in patients with coeliac disease than in normal controls or in the other patients studied is interesting in view of the enhanced jejunal secretion in this condition (Fordtran et al., 1967). However, it is surprising that, in the hypersecretive condition of cholera, Sachar et al. (1969) failed to observe significant changes in intestinal PD compared with normal subjects, whereas many experimental studies with cholera toxin have reported marked changes in PD (Moore et al., 1971; Field et al., 1972).

The association of motility with secretion has physiological as well as pathological implications. Because the presence of food in the small intestine stimulates motility (Hightower, 1968), an associated increase in secretion may well have functions of lubrication as well as diluting and mixing the chyme to facilitate digestion and absorption. Moreover, enhanced intestinal secretion may help to explain the diarrhoea associated with conditions characterised by small bowel hypermotility (Ritchie and Salem, 1965) and also the large volumes of fluid which collect proximal to intestinal obstruction. Combined PD and pressure recordings from the small intestine may provide a useful method of studying the changes in motility and electrogenic secreting activity in patients with intestinal disease.

We are grateful to Professor H. L. Duthie for the surgical preparation of the Thiry-Vella loops in the dog.

\section{References}

Brown, B. H., Holdsworth, C. D., Levin, R. J., Read, N.W., and Smallwood, R. H. (1976). The relationship between intestinal motility and fluctuations in transmural potential difference in the human jejunum. Journal of Physiology, 259, 29-30P.

Cooke, A. R. (1967). The glands of Brunner. In Handbook of Physiology, section 6, vol. 2, pp. 1087-1095. Edited by C. F. Code. American Physiological Society: Washington, D.C.

Crosby, W. H., and Kugler, H. W. (1957). Intraluminal biopsy of the small intestine; the intestinal biopsy capsule. American Journal of Digestive Diseases, New Series, 2, 236 241.

Field, M., Fromm, D., Al-Awqati, Q., and Greenough, W. B. (1972). Effect of cholera enterotoxin on ion transport across isolated ileal mucosa. Journal of Clinical Investigation, 51, 796-804.

Florey, H. W., Wright, R. D., and Jennings, M. A. (1941). The secretions of the intestine. Physiological Reviews, 21, 36-69.

Fordtran, J. S., Rector, F. C., and Carter, N. W. (1968). The mechanisms of sodium absorption in the human small intestine. Journal of Clinical Investigation, 47, 884-900.

Fordtran, J. S., Rector, F. C., Locklear, T. W., and Ewton, M. F. (1967). Water and solute movement in the small intestine of patients with sprue. Journal of Clinical Investigation, 46, 287-298.
Foulk, W. T., Code, C. F., Morlock, C. G., and Bargen, J (1954). A study of the motility patterns and the basic rhythm in the duodenum and upper part of the jejunum of human beings. Gastroenterology, 26, 601-611.

Friedman, G., Wolf, B. S., Waye, J. D., and Janowitz, H. D. (1965). Correlation of cineradiographic and intraluminal pressure changes in the human duodenum: an analysis of the functional significance of monophasic waves. Gastroenterology, 49, 37-49.

Gerard, J., Devroede, G., and Postaire, J. G. (1975). Relationship between intraluminal pressure and potential differences variations in the perfused rat colon. Gastroenterology, 68, A25/882.

Gregory, R. A. (1947). The nervous pathways of intestinal reflexes associated with nausea and vomiting. Journal of Physiology, 106, 95-103.

Gregory, R. A. (1962). The jejunal glands. In Secretorv Mechanisms of the Gastrointestinal Tract, pp. 213-229. Arnold: London.

Hardcastle, P. T., and Eggenton, J. (1973). The effect of acetylcholine on the electrical activity of intestinal epithelial cells. Biochimica et Biophysica Acta, 298, 95-100.

Hardcastle, P. T., and Hardcastle, J. (1976). Personal communication.

Herrin, R. C., and Meek, W. J. (1933). Distension as a factor in intestinal obstruction. Archives of Internal Medicine, 51, 152-168.

Hightower, N. C. (1968). Motor action of the small bowel. In Handbook of Physiology, section 6, vol. 4, pp. 2001-2024. Edited by C. F. Code. American Physiological Society: Washington, D.C.

Hubel, K. A. (1973). The influence of pilocarpine on net movement of ions and water in the jejunum and ileum of the anaesthetised rat. Gastroenterology, 64, A65/748.

Kazic, T., and Varagic, V. M. (1968). Effect of increased intraluminal pressure on the release of acetylcholine from the isolated guinea-pig ileum. British Journal of Pharmacology and Chemotherapy, 32, 185-192.

Matuchansky, C., Huet, P. M., Mary, J. Y., Rambaud, J. C., and Bernier, J. J. (1972). Effects of cholecystokinin and metoclopramide on jejunal movements of water and electrolytes and on transit time of luminal fluid in man. European Journal of Clinical Investigation, 2, 169-175.

Moore, W. L., Bieberdorf, F. A., Morawski, S. G., Finkelstein, R. A., and Fordtran, J. S. (1971). Ion transport during cholera-induced ileal secretion in the dog. Journal of Clinical Investigation, 50, 312-318.

Read, N. W., Holdsworth, C. D., and Levin, R. J. (1974). Electrical measurement of intestinal absorption of glucose in man. Lancet, 2, 624-627.

Read, N. W., Levin, R. J., and Holdsworth, C. D. (1976). Electrogenic glucose absorption in untreated and treated coeliac disease. Gut, 17, 444-449.

Ritchie, J. A., and Salem, S. N. (1965). Upper intestinal motility in ulcerative colitis, idiopathic steatorrhoea and the irritable colon syndrome. Gut, 6, 325-337.

Sachar, D. B., Taylor, J. O., Saha, J. R., and Phillips, R. A. (1969). Intestinal transmural electrical potential and its response to glucose in acute and convalescent cholera. Gastroenterology, 56, 512-521.

Savitch, V. V., and Sochestvensky, N. A. (1917). L'influence du nerf vague sur la sécrétion de l'intestin. Comptes Rendus des Séances et Mémoires de la Société de Biologie 80, 508-509.

Tidball, C. S. (1961). Active chloride transport during intestinal secretion. American Journal of Physiology, 200, 309-312.

Turnberg, L. A., Isaacs, P. E. T., Corbett, C. L., and Riley, A. K. (1976). In vitro behaviour of human jejunum and ileum: response to theophylline and acetylcholine. In 
Intestinal Ion Transport, pp. 339-344. Edited by J. W. L. Robinson. Medical and Technical Publishing: Lancaster.

Wingate, D. L., Green, R., Symes, J., and Pilot, M. (1974). Interpretation of fluctuation of transmural potential difference across the proximal small intestine. Gut, 15, 515520.

Wingate, D. L., Hayward, M. G., Johnson, C. M., Marczewski, A. G., Petty, R. G., and Wilson, E. J. (1973). Physio- logical changes in human transjejunal potential difference. Scandinavian Journal of Gastroenterology, 8, 473-478.

Wright, R. D., Jennings, M. A., Florey, H. W., and Lium, R. (1940). The influence of nerves and drugs on secretion by the small intestine and an investigation of the enzymes in intestinal juice. Quarterly Journal of Experimental Physiology, 30, 73-120. 